\title{
Alterations in blood pressure during exchange transfusion
}

\author{
JACOB V. ARANDA AND AVRON Y. SWEET*
}

From the Perinatal Clinical Research Center, and the Department of Pediatrics, Case Western Reserve University at Cleveland Metropolitan General Hospital, Cleveland, Ohio, USA

SUMMARY Blood pressure changes as a function of the rates of blood withdrawal and infusion were determined during exchange blood transfusion in 2 preterm newborn infants. $10 \mathrm{ml}$ blood withdrawal and infusion completed within 3 minutes resulted in reversible changes in aortic pressure, whereas the same procedure completed within 45 to 60 seconds resulted in a progressive fall in the systolic pressure and in narrowing of the pulse pressure. In one of the cases this was associated with respiratory arrest. An exchange rate of $5 \mathrm{ml} / \mathrm{kg}$ per 3 minutes is recommended.

At present there is no rational recommendation as to the rate at which exchange transfusion should be performed. Our observations of blood pressure (BP) during slow and fast exchange transfusion in 2 preterm infants are reported to illustrate that significant alterations in BP are associated with exchange transfusion and that these changes are partly rate dependent.

\section{Case reports}

Case 1. A male, weighing $2270 \mathrm{~g}$, of 36 weeks' gestation who had haemolytic disease of the newborn due to $R h$ incompatibility. Labour and delivery were uncomplicated and Apgar score at one minute was 8 . Physical findings at birth included jaundice, hepatomegaly, and splenomegaly.

Cord blood haematocrit was $37 \%$, serum total bilirubin concentration was $6 \cdot 3 \mathrm{mg} / 100 \mathrm{ml}(108$ $\mu \mathrm{mol} / \mathrm{l})$ of which $1.0 \mathrm{mg} / 100 \mathrm{ml}(17 \cdot 1 \mu \mathrm{mol} / \mathrm{l})$ was direct, blood group was $A B$, he was $R h$ positive and the direct Coombs's test was positive. Jaundice and pallor increased and at 6 hours of age serum total bilirubin concentration had risen to $12 \cdot 3 \mathrm{mg} / 100 \mathrm{ml}$ $(210 \mu \mathrm{mol} / \mathrm{l}$ ) (direct bilirubin $0.8 \mathrm{mg} / 100 \mathrm{ml}$; $13.7 \mu \mathrm{mol} / \mathrm{l})$ and the venous haematocrit had fallen to $20.5 \%$. The concentrations of serum protein and calcium were $39 \mathrm{~g} / 1$ and $8.8 \mathrm{mg} / 100 \mathrm{ml} \mathrm{(2.2} \mathrm{mmol} / \mathrm{l})$ respectively. Mild respiratory distress was noted and a no. 5 French Argyle umbilical artery catheter was inserted to the level of the third lumbar vertebra to

Received 15 December 1976

*Present address: Department of Pediatrics, Mount Sinai Medical Center, Fifth Avenue and 100th Streets, New York, N.Y. 10029. permit blood sampling for arterial blood $p \mathrm{H}, \mathrm{PCO}_{2}$, and $\mathrm{Po}_{2}$. Through this catheter aortic blood pressure was measured continuously by means of a HewlettPackard strain gauge and recorder.

An exchange transfusion was performed at 6 hours of age through an umbilical vein catheter (Argyl no. 5 French) whose tip was in the inferior vena cava. Slightly less than twice the estimated blood volume of the patient was used $(350 \mathrm{ml}$ fresh whole blood in acid citrate). To determine the effect of the rate of exchange transfusion on the BP, the exchange transfusion was divided into 5 phases. Phases I, III, and V were slow rate of transfusion periods wherein $10 \mathrm{ml}$ blood was withdrawn and $10 \mathrm{ml}$ infused within 3 minutes. Phases II and IV were fast rate of transfusion in which $10 \mathrm{ml}$ blood was removed and $10 \mathrm{ml}$ injected during 45 to 60 seconds. These rates were equivalent to $1.4 \mathrm{ml}$ of blood/ $\mathrm{kg}$ per min and 4.3 to $5.7 \mathrm{ml} / \mathrm{kg}$ per min for slow and fast exchange transfusions, respectively. Except for occasional difficulty in blood withdrawal resulting in a relatively longer withdrawal period (Fig. 2), the durations of infusion and withdrawal were usually equal. During each phase, $70 \mathrm{ml}$ blood was injected and $70 \mathrm{ml}$ removed. The infant was allowed to stabilize for 5 to 10 minutes between phases. Baseline aortic BPs were obtained before each phase. The change in BP during each phase was compared to the baseline pressure obtained before that phase was begun.

The haemodynamic alterations are shown in Fig. 1 and illustrated in Fig. 2A and B. During the slow exchange transfusion a fall in aortic systolic and mean BPs ranging from $6-21 \mathrm{mmHg}$ and 0-10 $\mathrm{mmHg}$, respectively, were noted at the com- 


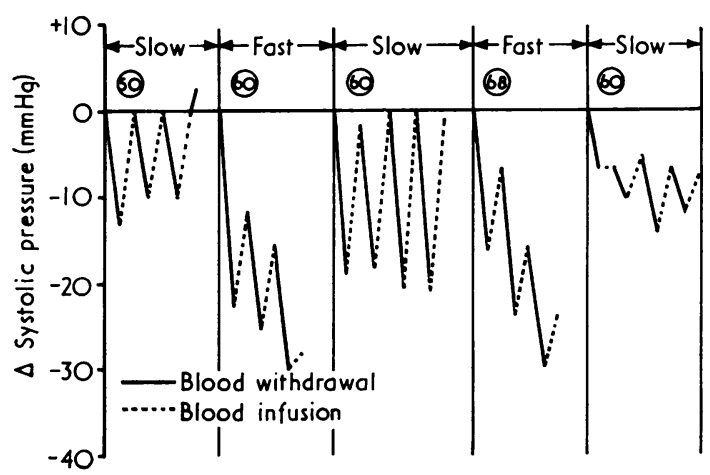

Fig. 1 Case 1. Changes in systolic BP. Blood was withdrawn and infused with an incremental volume of $10 \mathrm{ml}$ within 3 minutes (slow transfusion) or within 45 to 60 seconds (fast transfusion). Numbers in circles indicate baseline systolic pressures obtained before each phase of exchange transfusion.

pletion of each withdrawal of $10 \mathrm{ml}$ blood. However, the BP promptly returned to baseline or near baseline pressure as soon as $10 \mathrm{ml}$ blood was infused.
The changes in aortic BP during the fast phase were in contrast, as shown in Figs. 1 and $2 \mathrm{~A}, \mathrm{~B}$. The systolic and mean BPs decreased from 16 to $30 \mathrm{mmHg}$ and 6 to $18 \mathrm{mmHg}$, respectively, during blood withdrawal, without returning to baseline upon infusion. A narrowed pulse pressure and a decreased diastolic pressure were also noted. The heart rate ranged from 120 to 156 beats per minute and the respiratory rate from 60 to 72 per minute without obvious relationship to the rate of exchange transfusion.

The infant survived the procedure well and required two more exchange transfusions for hyperbilirubinaemia after which he progressively improved and was discharged at 15 days of age.

Case 2. A female, weighing $1900 \mathrm{~g}$, of 28 weeks' gestation who was hypotonic and cyanotic at birth and had an Apgar score of 3 at one minute. She was successfully resuscitated with intermittent positive pressure oxygen, but soon developed respiratory distress and had chest $x$-rays compatible with hyaline membrane disease. Arterial blood gases were monitored via an umbilical catheter (Argyle

(A)

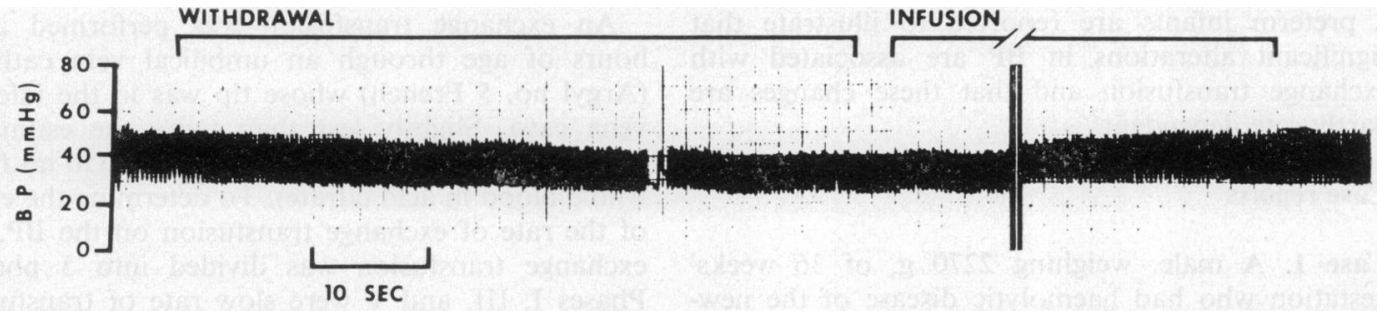

(B)

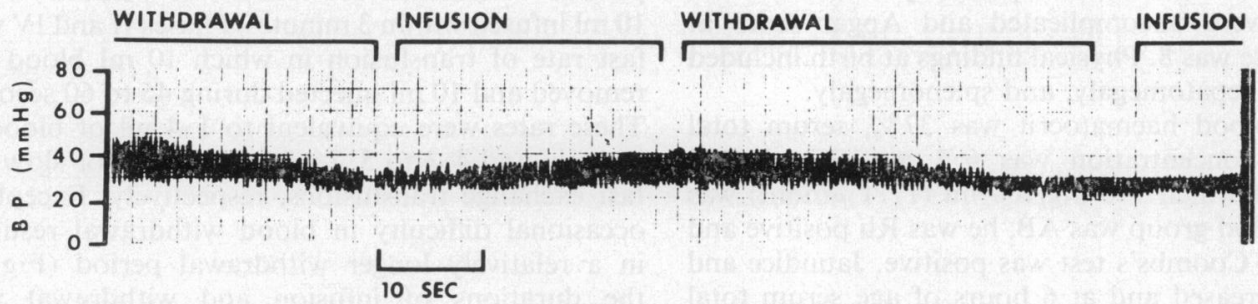

(C)

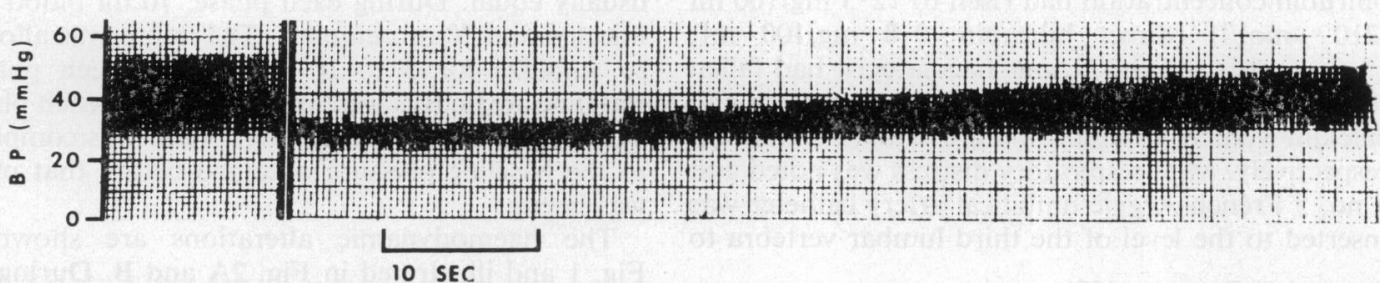

Fig. 2 Case 1. Changes in BP during exchange transfusion. $10 \mathrm{ml}$ blood was withdrawn and an equal volume was infused $(A)$ slowly, within 3 minutes, or $(B)$ fast, within 45-60 seconds. (C) Recovery to baseline pressure after infusion of $10 \mathrm{ml}$ blood at the end of a fast exchange transfusion. Baseline BP is shown separately at the left side. 
no. 5 French), and she required up to $90 \%$ of ambient oxygen to maintain adequate $\mathrm{PaO}_{2}$. On day 4 the respiratory distress improved, but increasing jaundice was noted. There was no blood type or Rhesus incompatibility between the infant and mother. Cord blood direct Coombs's test was negative.

An exchange transfusion using acid citrate dextrose anticoagulated blood (total volume $250 \mathrm{ml}$ ) was performed via an umbilical vein catheter (Argyle no. 5 French), the tip being in the inferior vena cava near the right atrium. Aortic blood pressure was monitored continuously using an umbilical artery catheter as in Case 1. To determine the effect of the rate of exchange transfusion on $\mathrm{BP}$, the procedure was divided into 5 phases as in Case 1 and using volumes of $10 \mathrm{ml}$ per infusion and withdrawal for both fast and slow phases (total of $50 \mathrm{ml}$ in and out for each phase). These rates were $1.8 \mathrm{ml}$ blood $/ \mathrm{kg}$ per min and 5.3 to $7 \mathrm{ml} / \mathrm{kg}$ per min for slow and fast exchange transfusions respectively. The BP was allowed to stabilize for 5 to 10 minutes between phases. There were haemodynamic alterations as shown in Fig. 3. During the period of slow exchange transfusion, a fall in aortic systolic and mean BP ranging from 2-17 $\mathrm{mmHg}$ and $0-10 \mathrm{mmHg}$ respectively were noted upon completion of the withdrawal of $10 \mathrm{ml}$ of blood. The fall in BP returned to baseline pressures upon infusion of $10 \mathrm{ml}$ blood.

As in Case 1, the changes in aortic BP during the fast phases were different (Fig. 3). The systolic and mean aortic pressures decreased from 4 to $32 \mathrm{mmHg}$ and 4 to $24 \mathrm{mmHg}$ respectively during the withdrawal period without returning to baseline pressures

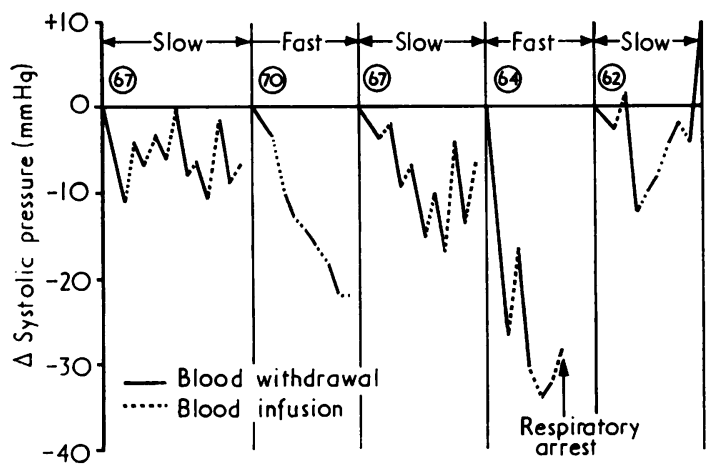

Fig. 3 Case 2. Changes in systolic BP. Blood was withdrawn and infused with an incremental volume of $10 \mathrm{ml}$ within 3 minutes (slow transfusion) or within 45 to 60 seconds (fast transfusion). Numbers in circles indicate baseline systolic pressures obtained before each phase of exchange transfusion. Respiratory arrest occurred during the second fast phase. upon transfusion. Instead there was a progressive incremental fall in BP so that at the end of the second phase the baby had a respiratory arrest; this responded well to positive pressure bagging with oxygen. The heart rate fell to 85 per minute during this episode of apnoea. The BP rose to baseline levels within 3 minutes from the onset of respiratory arrest and the baby was stable for 10 minutes before continuation of the last slow phase. She improved thereafter and was discharged aged 41 days.

\section{Discussion}

The observations of the aortic BP of the two infants show that marked fluctuations occur during exchange transfusions, and that the magnitude of the changes is largely dependent upon the rate of the withdrawal and infusion of blood to and from the inferior vena cava. These findings are consistent with the demonstration by Young and Cottom (1966) of a fall of $10 \mathrm{mmHg}$ in BP during a single withdrawal within 15 seconds of $20 \mathrm{ml}$ blood from a normal term infant.

The haemodynamic alterations during exchange transfusion may be due primarily to an altered venous return to the heart and to an acute change in the circulating blood volume. Altered venous return results in a change in cardiac output (Best and Taylor, 1966). Since cardiac output is a major determinant in the maintenance of arterial BP, changes in cardiac output would result in altered arterial BP. During exchange transfusion, the venous return to the heart could be significantly changed. In the newborn infant, the capacity of the right atrium is about 7 to $10 \mathrm{ml}$ (Rowe and Mehrizi, 1968). Withdrawal and infusion of 10 to $20 \mathrm{ml}$ blood within 20 seconds to 3 minutes during exchange transfusion alters the venous return to the heart, resulting in reduced cardiac output and decreased arterial BP. The demonstration by Wallgren et al. (1963) that a step-wise withdrawal of blood in erythroblastotic infants results in a fall of systolic BP indicates that the repeated withdrawal and infusion of blood during exchange transfusion also may cause significant fluctuations in BP.

Gupta and Scopes (1965) noted large and rapid fluctuations in BP during an exchange transfusion in a newborn infant; however their study did not determine the changes in BP as a function of the rate of withdrawal and infusion of blood. Their observations agree with the present report which shows that BP dropped when the blood was withdrawn and it rose when the blood was infused. In both preterm and term newborn infants, a reduction in blood volume of 10 to $20 \mathrm{ml}$, equivalent to about $10 \%$ of the circulating volume, over 15 seconds, 
causes a 15 to $30 \%$ reduction in both pulse and aortic mean pressure (Young, 1966). The decreased BP is restored to baseline upon replacement infusion of blood. That the rise to baseline pressure is completed by 2 minutes (Fig. 2C), partly explains the greater magnitude of $\mathrm{BP}$ changes during fast exchange transfusions wherein withdrawal of blood is performed before complete restoration to baseline pressure.

It is likely that too fast withdrawal is more harmful than too fast infusion. The former may result in a large fall in BP, whereas the latter may partly correct this change (Figs. 1, 2, 3). The large fall in BP during fast exchange may result in cardiorespiratory collapse attributed to decreased perfusion of vital organs and splanchnic vessels. Boggs and Westphal (1960) reported an $0.7 \%$ mortality occurring during exchange transfusion, which may have been attributed to large haemodynamic alterations during the procedure. In Case 2 respiratory arrest and bradycardia occurred during a fast phase when a decrease in the BP and marked narrowing of the pulse pressure were noted. Delayed complications may occur. Both colonic perforations (Orme and Eades, 1968; Friedman et al., 1970: Sommerschild, 1971) and necrotizing enterocolitis following exchange transfusions have been attributed to a decreased ileal and colonic blood flow during the procedure (Touloukian et al., 1973). These effects may be minimized by slow rate of transfusion manually by a syringe and/or by the use of a drip-method (Valaes, 1966) which allows slow infusion of blood. The present report suggests that withdrawal and infusion of blood at a rate of about $5 \mathrm{ml} / \mathrm{kg}$ over a period of 3 minutes result in minimal and reversible changes in BP.
Supported in part by USPHS grant RR 00210.

\section{References}

Best, C. H., and Taylor, N. B. (1966). The Physiological Basis of Medical Practice, 8th ed. Williams and Wilkins, Baltimore.

Boggs, T. R., and Westphal, M. C. (1960). Mortality of exchange transfusion. Pediatrics, 26, 745-755.

Friedman, A. B., Abellera, R. M., Lidskey, I., and Lubert, M. (1970). Perforation of the colon after exchange transfusion in the newborn. New England Journal of Medicine, 282, 796-797.

Gupta, J. M., and Scopes, J. W. (1965). Observations on blood pressure in newborn infants. Archives of Disease in Childhood, 40, 637-644.

Orme, R. l'E., and Eades, S. M. (1968). Perforation of the bowel in the newborn as a complication of exchange transfusion. British Medical Journal, 4, 349-351.

Rowe, R. D., and Mehrizi, A. (1968). The Neonate with Congenital Heart Disease, p. 5. Saunders, Philadelphia.

Sommerschild, H. C. (1971). Intestinal perforation in the newborn infant as a complication in umbilical vein infusion or exchange transfusion. Surgery, 70, 609-613.

Touloukian, R. J., Kadar, A., and Spencer, R. P. (1973). The gastrointestinal complications of neonatal umbilical venous exchange transfusion: a clinical and experimental study. Pediatrics, 51, 36-43.

Valaes, T. (1966). Exchange-transfusion apparatus. Lancet, $1,1215$.

Wallgren, G., Barr, M., and Rudhe, U. (1963). Blood pressure homeostasis in the newborn infant. Acta Paediatrica, 52, 214-215.

Young, M. (1966). Responses of the systemic circulation of the newborn infant. British Medical Bulletin, 22, 70-72.

Young, M. M., and Cottom, D. (1966). Arterial and venous blood pressure responses during a reduction in blood volume and hypoxia and hypercapnia in infants during the first two days of life. Pediatrics, 37, 733-742.

Correspondence to Dr. J. V. Aranda, McGill University, Montreal Children's Hospital, 2300 Tupper Avenue, Montreal, Quebec, Canada, H3H 1 P3. 